\title{
The HPV16 E1 Carboxyl Domain Provides a Helper Function for Adeno-Associated Virus Replication
}

\author{
Maohua Cao ${ }^{\mathrm{b}}$ Sarmistha Bandyopadhyay ${ }^{\mathrm{b}}$ Hongqing Zhu ${ }^{\mathrm{b}}$ Hong You $^{\mathrm{a}, \mathrm{b}}$ \\ Paul L. Hermonat ${ }^{a}$, b \\ ${ }^{a}$ Beijing Friendship Hospital, Capital Medical University, Beijing, China; bepartments of Obstetrics and Gynecology \\ and Internal Medicine, University of Arkansas for Medical Sciences, Little Rock, AR, USA
}

\section{Keywords}

Adeno-associated virus $\cdot$ Rep78 $\cdot$ Human papillomavirus

type $16 \cdot$ E1 protein $\cdot$ DNA replication

\begin{abstract}
Background/Aims: Recombinant adeno-associated virus (rAAV) is now in the clinic, yet production of rAAV remains problematic. We previously determined that human papillomavirus type 16 (HPV16) E1 protein boosts rAAV yields and E1 enhances AAV Rep78's replication-related biochemistries. Here, we deletion-mapped the helper domain within E1 to help glean its mechanism of action. Methods: Rep78E1 interaction was analyzed by Gal4-based yeast two-hybrid (Y2H)-cDNA assay. rAAV DNA replication was studied by AAV/helper plasmid transfection into HEK293 cells and Southern blot. Gene expression analysis was made of AAV and E1 plasmid transfection, CDNA generation, and then quantitative polymerase chain reaction. NCBI protein BLAST was used for the homology analysis. Results: Gal4-Y2HcDNA assay found in vivo Rep78-E1-binding activity across
\end{abstract}

M.C., S.B., and H.Z. contributed equally to this study.

\section{KARGER}

(๑) 2018 S. Karger AG, Basel

E-Mail karger@karger.com

www.karger.com/int
E1, but the carboxyl-third (amino acids [aa] 421-649) of E1 contained the predominant DNA replication helper domain. The amino-half of E1 (aa 1-337) inhibited transcription of rep ( 55 promoter) and cap (p40, trending lower) from non-replicating helper plasmid by quantitative (q)RT-PCR. Conclusions: The aa 421-649 helper domain of HPV16 E1 includes the ATP-binding/helicase region of E1 which boosts rAAV production and has homology with the analogous region of parvovirus NS-1/Rep78 by NCBI protein BLAST, suggesting these biochemistries are responsible for the mechanism of action in $\mathrm{E} 1$ helper function.

(c) 2018 S. Karger AG, Basel

\section{Introduction}

The determination of the genetics [1-3] and transcriptional regulation of the wild-type adeno-associated virus (wt AAV) genes $[4,5]$ and the subsequent development of methods to generate recombinant (r)AAV [6-12] have resulted in the continued climb of AAV as a useful gene

Paul L. Hermonat

Local Office

203 Lagoona Lane

Surfside Beach, TX 77541 (USA)

E-Mail aavguy123@yahoo.com

Hong You

Beijing Friendship Hospital, Capital Medical University

Yong An Road 95, Xicheng District

Beijing 100050 (China)

E-Mail youhong30@sina.com 
delivery vector. This basic work was first carried out in the laboratory in 1984 [6-9] in primary cells/animal models [13-19], and AAV is now one of the top clinical gene therapy vectors in use today [20-22]. While wt AAV will replicate in differentiating keratinocytes $[23,24]$ and certain cell lines (often with genotoxic stress) [25-28] in the laboratory, in tissue culture, most cell types AAV require co-infection by a helper virus, such as adenovirus (Ad), herpes simplex virus (HSV), or human papillomavirus (HPV), to allow productive AAV infection to occur [24, 29-31]. However, a recent study has shown that AAV is most often not found with associated Ad helper virus in clinical isolates, suggesting that AAV is likely a type of highly tropic ("picky") regular autonomous parvovirus [32]. Nevertheless, AAV is categorized as a Dependovirus, a genus of the family Parvoviridae, and AAV receives "helper functions" that are lacking in its own set of genes/ encoded proteins within its own genome. But this "lack" can be made up by providing a plasmid encoding the set of helper genes derived from its 3 helper viruses (usually Ad); this greatly increases the replication and burst size of wt AAV and recombinant (r)AAV in tissue culture [10-12].

AAV has a single-stranded DNA genome and encodes 2 large open-reading frames (ORF) [3]. While the right ORF, called cap, encodes the capsid (VP) proteins, the left ORF, called rep, encodes the replication (Rep) proteins [1, 2,33 . A total of 4 rep-encoded proteins are produced [33], and it is Rep78, the largest of these, which contains the full ORF-encoded amino acids. Most importantly, the Rep78 protein contains the critical biochemistries needed for AAV DNA replication, including binding to AAV inverted terminal repeat (ITR) DNA GAGC-trimer, endonuclease activity at the trs site of the ITR, and covalent protein attachment to ITR DNA exposed 5' phosphate simultaneously by this same endonuclease activity [34-37].

It is the critical and multifunctional Rep78 DNA replication (and transcriptional regulatory) protein of AAV which is likely a target of some of these helper proteins. In HPV, it is known that E1, E2, and E6 provide helper functions [24, 38], and it has been found that HPV16 E1 protein binds Rep78 in vitro and affects its replicationrelated biochemistries [37, 39]. The HPV16 E1 gene is the origin of the binding protein for HPV's own DNA replication, analogous to the AAV Rep78 protein, but lacks the analogous endonuclease and covalent attachment activities of the large AAV Rep proteins [40, 41]. The E1 helper protein enhances both autonomous wt AAV replication in differentiating keratinocytes and wt and rAAV production in HEK293 cells, the latter in conjunction with the Ad helper gene set $[24,38]$. However, it is unclear how this E1-stimulated enhancement of Rep78-DNA replication biochemistry actually takes place. To better understand E1's mechanism of helper function for Rep78driven AAV production, we analyzed both the aminoand carboxyl E1 fragment proteins for their ability to help wt AAV and rAAV replication, and it was found that the carboxyl region (aa 421-649) of E1 provided the helper function.

\section{Materials and Methods}

\section{Cells and Plasmids}

HEK293 cells were obtained from the American Type Culture Collection. HPV16 E1 deletion mutants were provided by Dr. Peter Howley (E1 aa 1-337, aa 1-190, aa 144-649, aa 335-649, aa 421-649, aa 44-337; wt E1 aa 1-649) [42, 43], and recloned into pCI-Neo (Promega, Madison, WI, USA) or pAD (Stratagene, CA, USA) vector for expression in mammalian cells. Plasmids AAV/ eGFP and pSH3 (equivalent to pDG) have been described previously $[11,12]$. Construction of plasmids pBD-Rep78 and pAD-Sp1 are described elsewhere [44-49]. The series of HPV16 E1 deletion plasmids were also recloned into pAD for analysis in the Gal4based yeast two-hybrid (Y2H)-cDNA assay, similar to our earlier studies [44-47]. There were no human or animal experiments undertaken in this study. All plasmids are available from the University of Arkansas for Medical Sciences, Department of Internal Medicine.

\section{Gal4-Y2H-cDNA Assay}

Basic reagents and protocols for this assay were procured from the HybriZap two-hybrid cDNA giga pack cloning kit (Stratagene, La Jolla, CA, USA). Yeast strain YRG-2 was transformed with the plasmid constructs using the lithium acetate method, and the transformed yeast clones were selected on medium lacking tryptophan and leucine. Transformed colonies and their $\beta$-galactosidase staining were observed.

\section{Southern Blot Analysis of wt AAV (pSM620) Replication}

with Ad

Subconfluent HEK293 cells were plated in a 6-well plate on the day before transfection. One microgram of pSM620 (wt AAV) wase cotransfected with $2 \mu$ of different HPV E1 deletion mutants or the control pCI plasmid with Fugene 6 (Roche, Indianapolis, IN, USA) as described in the manufacturer's protocol. After $12 \mathrm{~h}$, the DNA-lipid complexes were replaced with medium containing enough adenovirus type 5 to infect cells at a multiplicity of infection (MOI) of 5. At $48 \mathrm{~h}$ after infection, the low-molecular-weight DNA was extracted and digested with $D p n$ I to remove input plasmid DNA. Southern blots were performed on $9 \mu \mathrm{g}$ of digested DNA and probed with a ${ }^{32} \mathrm{P}$-labeled-AAV DNA probe.

Western Blot Analysis of Transfection Efficiency

HEK293 cells were transfected identically to those used for the analysis of DNA replication by Southern blot. All the E1 mutant expression plasmids included a neomycin ( $\mathrm{Neo}$ ) resistance gene 
(Neo), and therefore Neo can be used to measure transfection/expression efficiency. Whole cellular proteins were prepared as previously described [50], and then separated by electrophoresis on $10 \%$ SDS-polyacrylamide gel (Invitrogen) followed by being transferred to nitrocellulose membranes. After a blocking step with 5\% nonfat milk (Fisher-Scientific) for $1 \mathrm{~h}$ at room temperature, membranes were incubated overnight at $4{ }^{\circ} \mathrm{C}$ with primary antibodies (American Research Products) specific to human $\beta$-actin protein (1: 200 dilution) and Tn5 Neo protein (1: 200 dilution). Membranes were then washed with $1 \times$ TBST buffer $(10 \mathrm{mM}$ Tris- $\mathrm{HCl}$ [pH 7.5], $150 \mathrm{~mm} \mathrm{NaCl}, 0.1 \%$ Tween 20) and incubated with (1: 2,000 dilution) HRP-conjugated secondary antibody at room temperature for $1 \mathrm{~h}$. Proteins were detected using the ECL system (Fisher-Scientific Pierce).

\section{Analysis of rAAV DNA Replication by Southern Blot}

When studying rAAV DNA replication, $10 \mathrm{~cm}$ plates of $70 \%$ confluent HEK293 cells were transfected with $4 \mu \mathrm{g}$ each of $\mathrm{pAAV} /$ eGFP and pSH3 using FuGENE-6 as per the manufacturer's instructions. Five days after transfection, low-molecular-weight Hirt DNA was isolated [1,6], agarose gel-electrophoresed, subjected to Southern blotting as described previously [36-38], and then probed with ${ }^{32} \mathrm{P}-\mathrm{eGFP}$ DNA. No Dpn I digestion is needed at this late time of harvest as all transfected input plasmid DNA has been degraded by day 3 .

\section{Analysis of $r A A V$ Virus Production}

Plates of transfected HEK293 cells were freeze-thawed 3 times, cellular debris pelleted by centrifugation at 7,000 rpm for $25 \mathrm{~min}$, and the supernatant was then pushed through a $0.22-\mu \mathrm{m}$ filter. Three hundred micro-liters of virus stock was treated with 20 units DNase for $30 \mathrm{~min}$ at $37^{\circ} \mathrm{C}$. After heating the sample for $10 \mathrm{~min}$ at $100^{\circ} \mathrm{C}$, the sample was digested with proteinase $\mathrm{K}(0.2 \mu \mathrm{g} / \mathrm{mL})$ for $4 \mathrm{~h}$, phenol-extracted, and then ethanol-precipitated. The resulting DNA underwent agarose gel electrophoresis and Southern blotting, and then probed with ${ }^{32} \mathrm{P}$-eGFP DNA when analyzing for rAAV production, or ${ }^{32} \mathrm{P}$-pSM620 DNA when analyzing for wt AAV production.

\section{Analysis of Viral $m R N A$}

The RNeasy mini kit (Qiagen) was used to isolate total RNA from cells; this was then treated with DNase I. The transcriptor first strand cDNA synthesis kit (Roche) was used to synthesize cDNA using an anchored oligo(dT) primer. The resulting cDNA was then used for qRT-PCR analysis. The housekeeping gene $\beta$-actin was subjected to $\mathrm{qRT}$-PCR as the internal control for quantitation. The primer pairs specific to AAV genomic rep gene (forward: 5' -CCG TGG CCG AGA AGC TGC AG-3', reverse: 5'-CCA CGA GCA CGT GCA TGT GG-3'), cap gene (forward: $5^{\prime}$-GAC CGG CAG CTC GAC AGC GG-3', reverse: $5^{\prime}$-GCC TGG AAG ACT GCT CGT CC- $3^{\prime}$ ), and $\beta$-actin (forward: $5^{\prime}$-ATC TGG CAC CAC ACC TTC TAC-3', reverse: $5^{\prime}$-GAA GGT CTC AAA CAT GAT CTG G-3') were synthesized by Integrated DNA Technologies, Inc. (Coralville, IA, USA). RT-PCR was carried out on a $7900 \mathrm{HT}$ fast real-time PCR system using SYBR ${ }^{\circledR}$ Green master mix (Applied Biosystems), with cycle parameters of initial denaturation at $95^{\circ} \mathrm{C}$ for $10 \mathrm{~min}, 40$ denaturation cycles at $95^{\circ} \mathrm{C}$ for $15 \mathrm{~s}$, annealing at $60^{\circ} \mathrm{C}$ for $1 \mathrm{~min}$, and a dissociation step. Data analysis was executed by $7900 \mathrm{HT}$ fast system sequence detection software.

Core HPV16 E1 Helper Domain for AAV

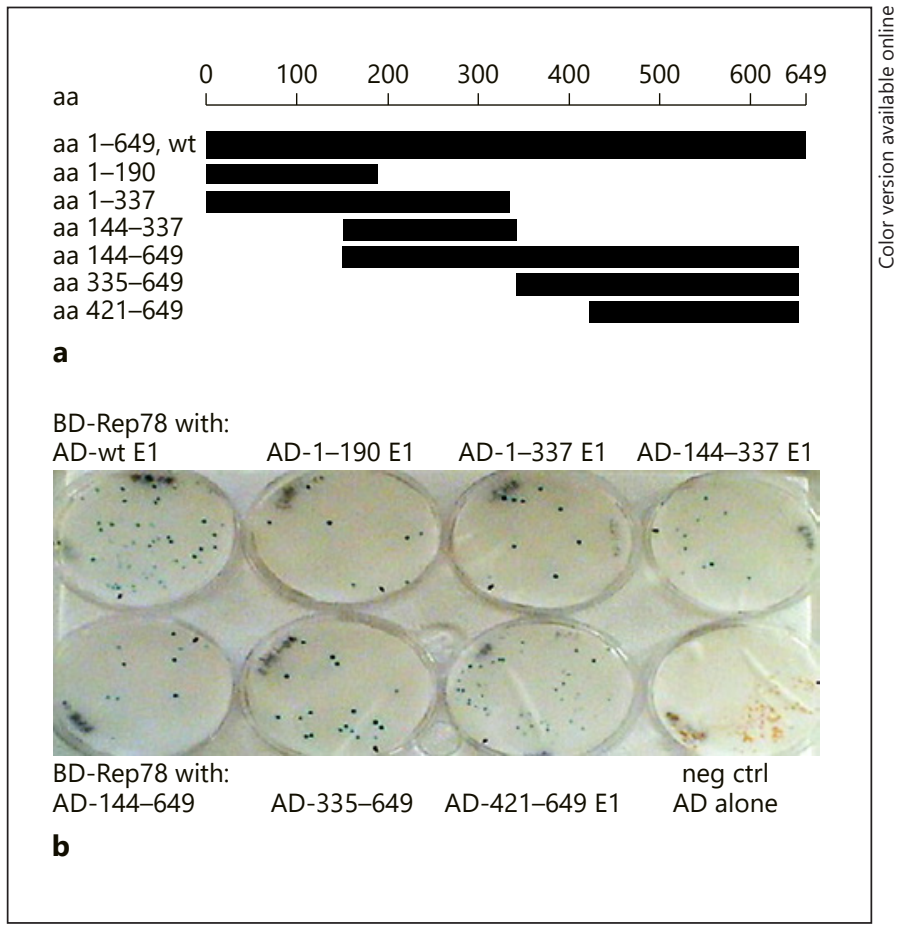

Fig. 1. E1 binds Rep78. a Map of the E1-nested deletion mutants used. b Gal4-Y2H-cDNA analysis of E1 mutant binding to Rep78. Note that 2 Rep78-binding domains are evident in E1 as indicated by $\beta$-galactosidase staining. Both E1/aa 1-337 and E1/aa 421-649 bind Rep78. neg ctrl, negative control.

\section{Results}

\section{E1 Binds Rep78 in Vivo}

To better understand E1's mechanism of helper function for AAV, we deletion-mapped various functional domains with E1 using the E1 helper- and Rep78-binding domains within E1. Interaction with Rep78 is one possibly important phenotype which needed mapping. Thus, utilizing a series of nested deletion mutants of E1 (provided by Peter Howley) we utilized the Gal4-Y2H-cDNA assay to observe Rep78-E1 binding. As we have done previously, Rep78 was fused with the Gal4-DNA-binding domain and the various E1 components fused with the Gal4 transactivation domain. The structure of E1 mutants used in this and other experiments is depicted in Figure 1a, and the results are shown in Figure 1b. Note that all of the truncated E1 proteins exhibited binding of Rep78 as indicated by $\beta$-galactosidase-positive (blue color) staining, compared to the negative control Rep78-BD-plus-AD, which gave no color. These data suggest that there are 2 Rep78-binding domains in E1; 1 in the amino-half (aa1337) and another in the carboxyl-half (aa 421-649. 


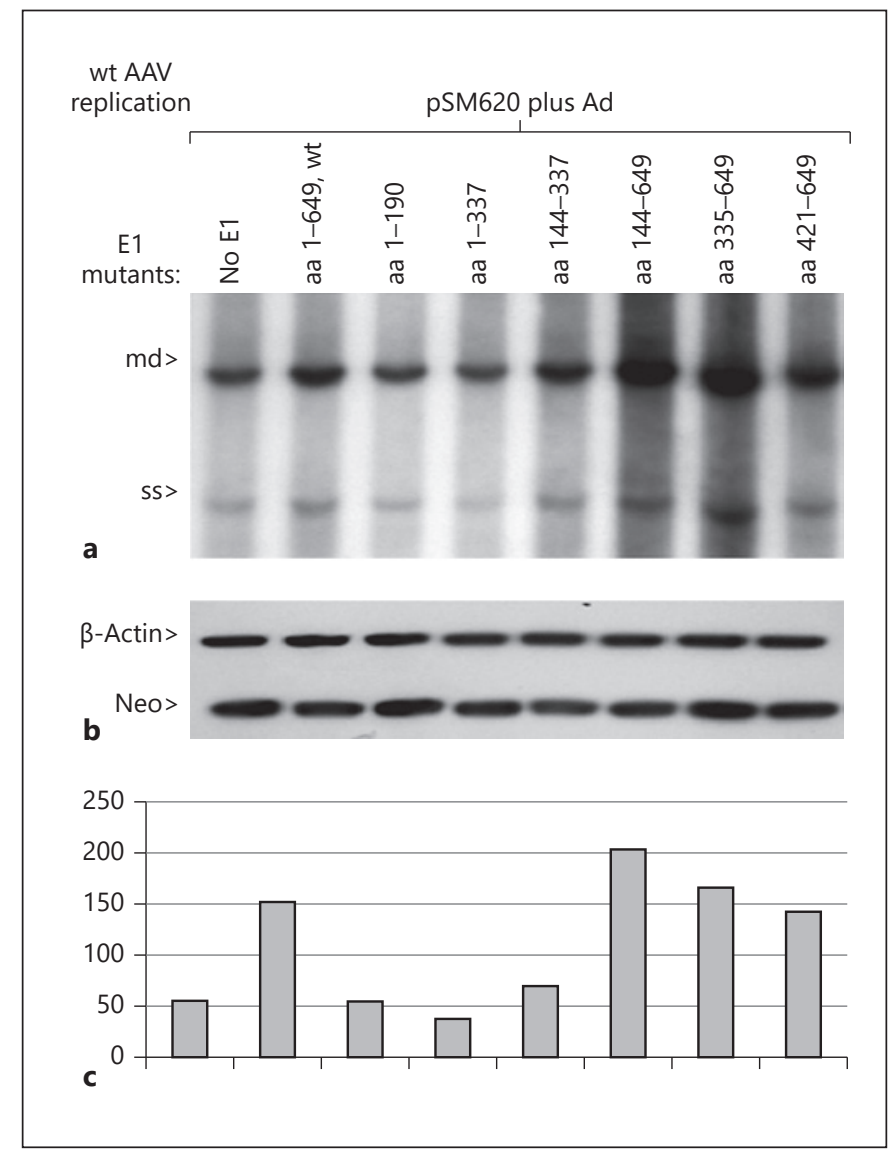

Fig. 2. E1/aa 421-649 helps wild-type (wt) AAV2 to replicate. a Representative of 3 Southern blots on the helper activities of the E1 subfragments for wt AAV2 DNA replication. These plasmids were transfected along with pSM620 (wt AAV2 plasmid) into Adinfected HEK293 cells. At $36 \mathrm{~h}$ after transfection, Hirt DNA was extracted, agarose gel-electrophoresed, and probed for AAV sequences. b Analysis of transfection efficiency by analyzing wholecell proteins which were electrophoresed, Western blotted, and probed with anti- $\beta$-actin and anti-Neo antibodies. c Quantification of the results of 3 such experiments ( 1 of which is shown in a). Note that the E1/aa 421-649 domain was able to significantly help wt AAV2 to replicate.

\section{E1/aa 421-649 Domain Helps wt AAV Replication in HEK293 Cells}

Previously, we found that E1 aa353-649 was able to provide some helper function, in boosting basal autonomous wt AAV2 DNA replication in differentiating keratinocytes [36]. However, wt AAV2 biology studies and rAAV production are almost always carried out in HEK293 cells. Therefore, the series of E1-nested deletion mutants placed into mammalian expression plasmids, and expressed from the CMV promoter, was assayed for the ability to boost wt AAV DNA replication along with wt adenovirus 5 coinfection of HEK293 cells. As shown in Figure 2a, representative of 3 experiments, the helper domain was defined by the smallest E1 carboxyl mutant (aa 421-649). Figure 2b shows a Western blot analysis of transfection efficiency where Neo protein represents transfected plasmid DNA expression, and $\beta$-actin represents cellular expression. Figure $2 \mathrm{C}$ shows quantification as a mean of 3 such experiments. Therefore, the minimal helper domain of E1 is composed of aa 421-649.

\section{E1/aa 421-649 Domain Helps rAAV Production in HEK293 Cells}

This same series of E1-nested deletion mutants in mammalian expression plasmids was assayed for the ability to boost $\mathrm{rAAV} / \mathrm{eGFP}$ DNA replication along with the adenovirus/AAV helper plasmid pSH3 [12], again transfected into HEK293 cells. Southern blot of rAAV DNA replication (Hirt DNA isolation) within the HEK293 cells is shown in Figure $3 \mathrm{a}$ and quantification of the DNA replication in Figure 3b. Southern blot of virions produced (i.e., DNase-resistant virion DNA) is shown in Figure 3c and quantification of the DNA replication in Figure $3 \mathrm{~d}$. These results are very similar to the deletion mutant helper activity analysis of wt AAV replication (Fig. 2), and further indicate that the core helper function domain of E1 is located at aa $421-649$.

\section{E1/aa1-337 Domain Inhibits Rep Expression from the Helper Plasmid}

Finally, we analyzed the expression of rep and cap mRNA from the pSH3 helper plasmid by qRT-PCR. Surprisingly, the results in Figure $4 \mathrm{a}$ (rep) and b (cap), suggest that E1 does modestly affect the expression of AAV p5 (rep) $(p<0.05)$ and p40 (cap, trending lower), from the nonreplicating helper plasmid. In contrast, full-length E1 and E1/aa 421-649 trended towards mRNA expression when compared to others, with E1/aa 421-649 trending towards upregulated expression more than wt E1 did.

\section{Discussion}

Our data demonstrate that the E1 helper domain for both wt AAV and rAAV DNA replication/virion production within HEK293 cells resides in aa 421-649. This finding is important as HEK293 cells are the workhorse cells for the generation of rAAV for gene therapy, as well as when studying wt AAV2 molecular biology. As the aa 421-649 E1 subfragment has equal (and trends towards higher) helper activity to full-length E1, this is fully con- 


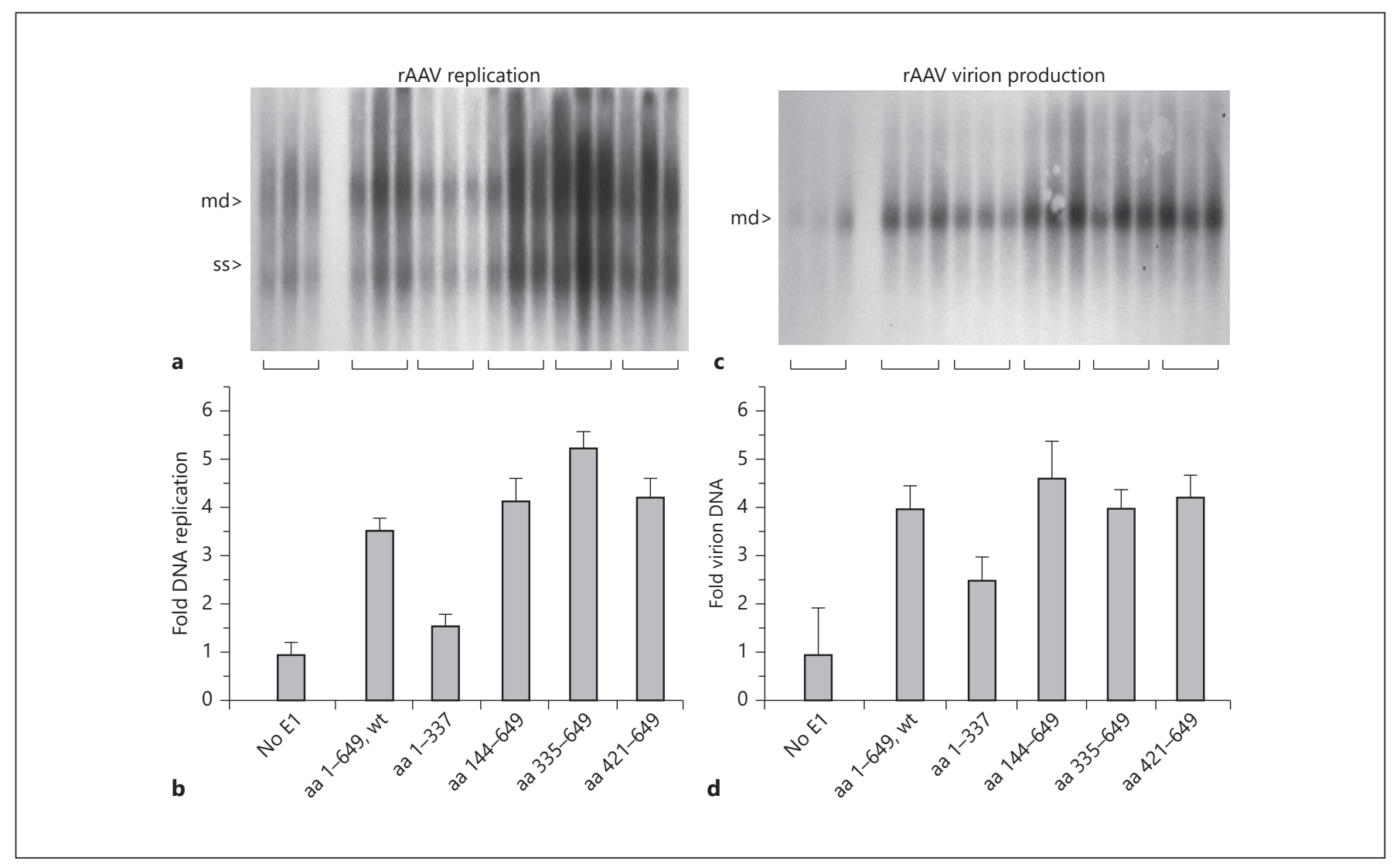

Fig. 3. E1/aa 421-649 helps rAAV DNA replication and virion production. a Representative Southern blot of the helper activities of the E1 subfragments for $\mathrm{rAAV} 2 / \mathrm{eGFP}$ DNA replication. HEK293 cells were transfected with AAV/eGFP and pSH3 Ad/AAV helper plasmid as described in Materials and Methods. At $12 \mathrm{~h}$ after transfection, the indicated E1 mutant expression plasmid was transfected. At day 5, Hirt DNA was extracted, agarose gel-electropho- resed, and probed for AAV sequences. b Quantification of the density of the lanes of the autoradiograph shown in a. c A similar analysis to a, except that this is of encapsidated virion AAV/eGFP DNA. d Quantification of the density of the lanes of the autoradiograph in c. a, c Note that the E1/aa 421-649 domain was able to significantly help both $\mathrm{rAAV} 2 / \mathrm{eGFP}$ DNA replication and virion production. wt, wild-type.
Fig. 4. E1 affects rep and cap expression from the nonreplicating helper plasmid. qRT-PCR analysis was carried out on rep and cap expression as described in Materials and Methods. Note that E1/aa 1-137 was significantly lower for rep and trended lower for cap expression than full-length E1 did. wt, wild-type.

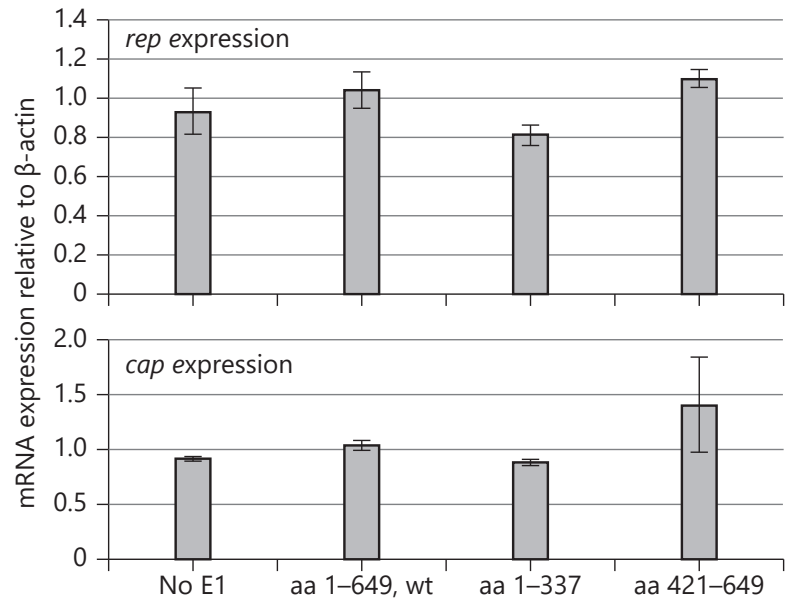


Fig. 5. E1/aa 421-649 shows homology to parvovirus NS-1. A standard NCBI protein BLAST homology search of HPV16 E1 aa 421-649 sequences against porcine parvovirus NS-1 P18547.2. The ATP recognition sites of both E1 and NS-1 are shown in aqua highlight.

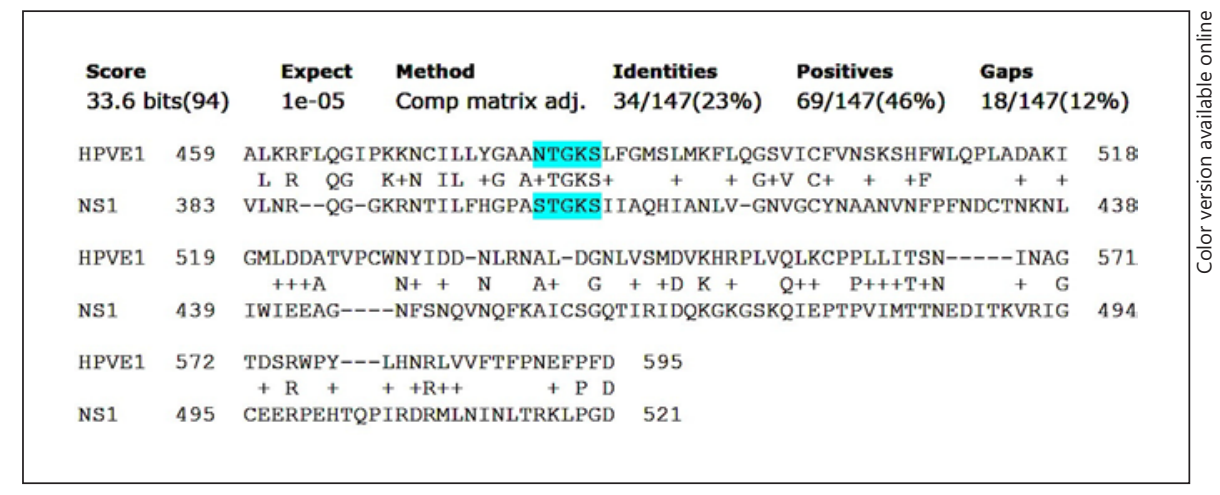

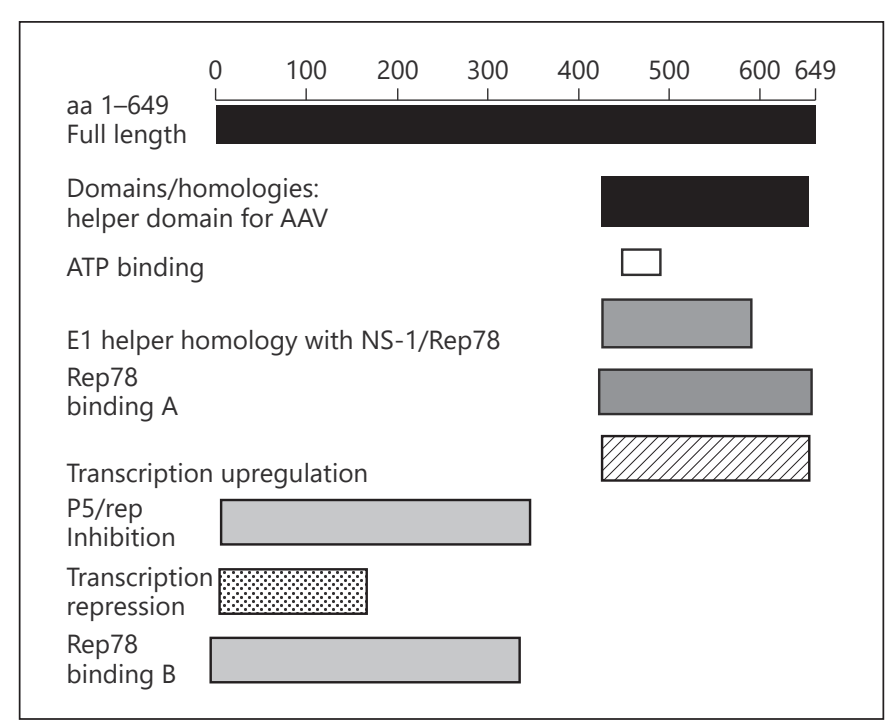

Fig. 6. Map of E1 helper and homologies. A compilation of the mapping results and known functions and homologies of E1. The known activity is shown listed to the left of the respective region of E1, shown on the right.

sistent with the aa 421-649 domain having the same ability to upregulate the Rep78-replication-related-biochemistries (ITR DNA-binding, trs nickase activity, and covalent attachment) as the full-length E1 protein itself, which we have documented previously [37]. Additionally, it was surprising that there is $>1$ Rep78-binding domain across the length of E1, as revealed by our Gal4-Y2H-cDNA analysis. We interpret these data most straightforwardly as there being 2 E1-binding-Rep78 domains, 1 in the amino-half and 1 in the carboxyl-half, even if we did not map these exactly. It is the carboxyl-E1-Rep78-binding domain which must be involved its helper function and is also likely tied to the up-regulation of Rep78-replicationrelated biochemistries. However, it was also apparent that the $\beta$-Gal activity (blue color) of the aa $421-649$ E1 colonies was slightly weaker than that of the aa 335-649 E1 colonies (NIH ImageJ-derived densities for aa 335-649, aa $421-649$, and negative control colonies as being $90+/-$ $9,42+/-8$, and $16+/-4$, respectively), which suggests that this more-truncated E1 form is somewhat weaker in Rep78-binding, and that the full Rep78-binding site may extend further upstream than aa 421 .

Another finding was that E1 aa 1-337 showed transcriptional inhibition of AAV, more specifically inhibiting the expression of both rep (p5 promoter) $(p<0.05)$ and cap (p40 promoter, trending lower) in a non-replicating system (the helper plasmid) (Fig. 4). But this was a mild phenotype, not a strong inhibition. This finding of inhibition of AAV transcription is in contrast to our previous studies where E1 was found to be a significant upregulator of rep and cap expression [24]. However, these earlier studies of E1 help were in a fully productive system with wt AAV (simultaneous DNA replication and virion production). In the nonreplicating system used in this study, E1/aa 1-337 inhibited rep and trended lower for cap mRNA expression when compared with no E1. Expression of rep and cap with E1/aa 1-337 was also significantly lower than when helped by full-length E1(aa 1-649). While inhibition of transcription by E1 has been seen before, the situation was not similar, as bovine papillomavirus (BPV) E1 was found to inhibit E2-stimulated BPV-based transcription [49]. E2-stimulated transcription was not included in our analysis.

The finding of a discreet E1 helper domain (aa 421-649) for AAV further refines our previously published data on primary keratinocytes. Additionally, the interesting transcriptional regulation of the rep and cap genes shows a complexity of activities by the E1 protein, once thought only to be a simple helicase. Moreover, because of a potential overlap in activities, we assayed homology between 
HPV16 E1 and porcine parvovirus NS-1 (Rep78) and found significant homology of E1 aa 459-595 and NS-1 aa $383-521$ in $>21 \%$ of the region of E1 (Fig. 5). This homology includes the ATP-binding site and helicase region of both E1 and NS-1, strongly suggesting that the E1 helper domain may be a complete "machine" of some type, being able to bind Rep78, have ATP hydrolysis, and possibly helicase activity. However, this homology does strongly imply that this domain has the full DNA-binding helicase activity, as HPV16 E2 protein is required for E1's helicase activity on the HPV ori. Perhaps Rep78 might function like $\mathrm{E} 2$, bringing the E1 helicase helper into a situation for stronger binding of DNA (ori DNA). This is presently mere speculation. Then, again, adding confusion to determining the mechanism of helper action, Rep78 has its own helicase function. An overview of our findings is shown in Figure 6 in a map of E1 helper domains and homologies. Further investigations into the specific mechanism of action of the core E1 helper domain, aa 421-649, are warranted, and these will include a repeat analysis of the 3 central replication-related-Rep78-ITR biochemistries (ITR DNA binding, trs nickase activity, and covalent attachment), as well as an analysis or repeat of the in vitro AAV DNA replication assays with E1/aa 421-649.

\section{Conclusions}

HPV16 E1 aa 421-649 contains the helper function for wt AAV and rAAV DNA replication and includes the ATP-binding/helicase region of E1. This region also has homology with the analogous region of parvovirus NS-1/ Rep78 by NCBI protein BLAST search, and is able to bind Rep78, have ATP-hydrolysis, possibly also showing helicase activity. These data improve our understanding of E1's helper function, which is made likely by augmenting Rep78's own biochemical activity as well as providing for the practical benefit of boosting rAAV production by using E1/aa 421-649 in conjunction with the Ad helper gene set.

\section{Acknowledgements}

We wish to thank Drs. Peter M. Howley and James P. Trempe for the E1 nest deletion plasmids and $\mathrm{pSH} 3$, respectively.

\section{Disclosure Statement}

The authors declare no conflicts of interest.

\section{Funding Sources}

There was no formal funding for this research.

\section{Author Contributions}

C.M., S.B., and Z.H. carried out the experiments, and reviewed and improved the paper. Y.H. and P.L.H. provided the original ideas and experimental structure and wrote the initial draft.

\section{References}

1 Hermonat PL, Labow MA, Wright R, Berns KI, Muzyczka N. Genetics of adeno-associated virus: isolation and preliminary characterization of adeno-associated virus type $2 \mathrm{mu}$ tants. J Virol. 1984 Aug;51(2):329-39.

2 Tratschin JD, Miller IL, Carter BJ. Genetic analysis of adeno-associated virus: properties of deletion mutants constructed in vitro and evidence for an adeno-associated virus replication function. J Virol. 1984 Sep;51(3):6119.

3 Srivastava A, Lusby EW, Berns KI. Nucleotide sequence and organization of the adeno-associated virus 2 genome. J Virol. 1983 Feb;45(2): 555-64.

4 Labow MA, Hermonat PL, Berns KI. Positive and negative autoregulation of the adeno-associated virus type 2 genome. J Virol. 1986 Oct;60(1):251-8.
5 Tratschin JD, Tal J, Carter BJ. Negative and positive regulation in trans of gene expression from adeno-associated virus vectors in mammalian cells by a viral rep gene product. Mol Cell Biol. 1986 Aug;6(8):2884-94.

6 Hermonat PL, Muzyczka N. Use of adeno-associated virus as a mammalian DNA cloning vector: transduction of neomycin resistance into mammalian tissue culture cells. Proc Natl Acad Sci USA. 1984 Oct;81(20):6466-70.

7 Hermonat PL. The first adeno-associated virus gene transfer experiment, 1983. Hum Gene Ther. 2014 Jun;25(6):486-7.

8 Cao M, You H, Hermonat PL. The X gene of adeno-associated virus 2 (AAV2) is involved in viral DNA replication. PLoS One. 2014 Aug;9(8):e104596.
9 Tratschin JD, West MH, Sandbank T, Carter BJ. A human parvovirus, adeno-associated virus, as a eucaryotic vector: transient expression and encapsidation of the procaryotic gene for chloramphenicol acetyltransferase. Mol Cell Biol. 1984 Oct;4(10):2072-81.

10 Matsushita T, Elliger S, Elliger C, Podsakoff G, Villarreal L, Kurtzman GJ, et al. Adenoassociated virus vectors can be efficiently produced without helper virus. Gene Ther. 1998 Jul;5(7):938-45.

11 Grimm D, Kern A, Rittner K, Kleinschmidt JA. Novel tools for production and purification of recombinant adenoassociated virus vectors. Hum Gene Ther. 1998 Dec;9(18): 2745-60.

12 Collaco RF, Cao X, Trempe JP. A helper virusfree packaging system for recombinant adeno-associated virus vectors. Gene. 1999 Oct: 238(2):397-405. 
13 LaFace D, Hermonat P, Wakeland E, Peck A. Gene transfer into hematopoietic progenitor cells mediated by an adeno-associated virus vector. Virology. 1988 Feb;162(2): 483-6.

14 Zhang JF, Hu C, Geng Y, Blatt LM, Taylor MW. Gene therapy with an adeno-associated virus carrying an interferon gene results in tumor growth suppression and regression. Cancer Gene Ther. 1996 Jan-Feb;3(1):31-8.

15 Ali RR, Reichel MB, Thrasher AJ, Levinsky RJ, Kinnon C, Kanuga N, et al. Gene transfer into the mouse retina mediated by an adeno-associated viral vector. Hum Mol Genet. 1996 May;5(5):591-4.

16 Kessler PD, Podsakoff GM, Chen X, McQuiston SA, Colosi PC, Matelis LA, et al. Gene delivery to skeletal muscle results in sustained expression and systemic delivery of a therapeutic protein. Proc Natl Acad Sci USA. 1996 Nov;93(24):14082-7.

17 Cao M, Theus SA, Straub KD, Figueroa JA, Mirandola L, Chiriva-Internati M, et al. AAV2/8-humanFOXP3 gene therapy shows robust anti-atherosclerosis efficacy in LDLRKO mice on high cholesterol diet. J Transl Med. 2015 Jul;13(1):235.

18 Zhu H, Cao M, Mirandola L, Figueroa JA, Cobos $\mathrm{E}$, Chiriva-Internati $\mathrm{M}$, et al. Comparison of efficacy of the disease-specific LOX1- and constitutive cytomegalovirus-promoters in expressing interleukin 10 through adeno-associated virus $2 / 8$ delivery in atherosclerotic mice. PLoS One. 2014 Apr;9(4):e94665.

19 Afione SA, Wang J, Walsh S, Guggino WB, Flotte TR. Delayed expression of adeno-associated virus vector DNA. Intervirology. 1999; 42:213-20.

20 Buchlis G, Podsakoff GM, Radu A, Hawk SM, Flake AW, Mingozzi F, et al. Factor IX expression in skeletal muscle of a severe hemophilia $B$ patient 10 years after AAV-mediated gene transfer. Blood. 2012 Mar;119(13):3038-41.

21 Salmon F, Grosios K, Petry H. Safety profile of recombinant adeno-associated viral vectors: focus on alipogene tiparvovec $\left(\right.$ Glybera ${ }^{\circledR}$ ). Expert Rev Clin Pharmacol. 2014 Jan;7(1):53-65.

22 Dias MF, Joo K, Kemp JA, Fialho SL, da Silva Cunha A Jr, Woo SJ, et al. Molecular genetics and emerging therapies for retinitis pigmentosa: basic research and clinical perspectives. Prog Retin Eye Res. 2017;S1350-9462(17): 30052-6.

23 Meyers C, Mane M, Kokorina N, Alam S, Hermonat PL. Ubiquitous human adeno-associated virus type 2 autonomously replicates in differentiating keratinocytes of a normal skin model. Virology. 2000 Jul;272(2):338-46.

24 You H, Liu Y, Prasad CK, Agrawal N, Zhang D, Bandyopadhyay S, et al. Multiple human papillomavirus genes affect the adeno-associated virus life cycle. Virology. 2006 Jan; 344(2):532-40.

25 Yakobson B, Koch T, Winocour E. Replication of adeno-associated virus in synchro- nized cells without the addition of a helper virus. J Virol. 1987 Apr;61(4):972-81.

26 Yalkinoglu AO, Heilbronn R, Bürkle A, Schlehofer JR, zur Hausen H. DNA amplification of adeno-associated virus as a response to cellular genotoxic stress. Cancer Res. 1988 Jun;48(11):3123-9.

27 Nicolas A, Jolinon N, Alazard-Dany N, Barateau V, Epstein AL, Greco A, et al. Factors influencing helper-independent adeno-associated virus replication. Virology. 2012 Oct; 432(1):1-9.

28 Kang BY, You H, Bandyopadhyay S, Agrawal $\mathrm{N}$, Melchert RB, Basnakian AG, et al. Cervical cancer isolate PT3, super-permissive for adeno-associated virus replication, over-expresses DNA polymerase $\delta, \mathrm{PCNA}, \mathrm{RFC}$ and RPA. BMC Microbiol. 2009 Apr;9(1):79.

29 Casto BC, Atchison RW, Hammon WM. Studies on the relationship between adenoassociated virus type I (AAV-1) and adenoviruses. I. Replication of AAV-1 in certain cell cultures and its effect on helper adenovirus. Virology. 1967 May;32(1):52-9.

30 Buller RM, Janik JE, Sebring ED, Rose JA Herpes simplex virus types 1 and 2 completely help adenovirus-associated virus replication. J Virol. 1981 Oct;40(1):241-7.

31 Meyers C, Alam S, Mane M, Hermonat PL. Altered biology of adeno-associated virus type 2 and human papillomavirus during dual infection of natural host tissue. Virology. 2001 Aug;287(1):30-9.

32 Chen CL, Jensen RL, Schnepp BC, Connell MJ, Shell R, Sferra TJ, et al. Molecular characterization of adeno-associated viruses infecting children. J Virol. 2005 Dec;79(23):1478192.

33 Trempe JP, Mendelson E, Carter BJ. Characterization of adeno-associated virus rep proteins in human cells by antibodies raised against rep expressed in Escherichia coli. Virology. 1987 Nov;161(1):18-28.

34 Snyder RO, Im DS, Muzyczka N. Evidence for covalent attachment of the adeno-associated virus (AAV) rep protein to the ends of the AAV genome. J Virol. 1990 Dec;64(12):620413.

35 Batchu RB, Miles DA, Rechtin TM, Drake RR, Hermonat PL. Cloning, expression and purification of full length Rep78 of adeno-associated virus as a fusion protein with maltose binding protein in Escherichia coli. Biochem Biophys Res Commun. 1995 Mar;208(2): 714-20.

36 Bishop BM, Santin AD, Quirk JG, Hermonat PL. Role of the terminal repeat GAGC trimer, the major Rep78 binding site, in adeno-associated virus DNA replication. FEBS Lett. 1996;397(1):97-100.

37 Bandyopadhyay S, Cao M, Liu Y, Hermonat PL. HPV E1 up-regulates replication-related biochemistries of AAV Rep78. Virology. 2010 Jun;402(1):94-101.

38 Cao M, Zhu H, Bandyopadhyay S, You H, Hermonat PL. HPV-16 E1, E2 and E6 each complement the Ad5 helper gene set, increasing rAAV2 and wt AAV2 production. Gene Ther. 2012 Apr;19(4):418-24.

39 Bandyopadhyay S, Raney KD, Liu Y, Hermonat PL. AAV-2 Rep78 and HPV-16 E1 interact in vitro, modulating their ATPase activity. Biochemistry. 2008 Jan;47(2):84556.

40 Wilson VG, West M, Woytek K, Rangasamy D. Papillomavirus E1 proteins: form, function, and features. Virus Genes. 2002 Jun; 24(3):275-90.

41 Hughes FJ, Romanos MA. E1 protein of human papillomavirus is a DNA helicase/ ATPase. Nucleic Acids Res. 1993 Dec;21(25): 5817-23.

42 Yasugi T, Benson JD, Sakai H, Vidal M, Howley PM. Mapping and characterization of the interaction domains of human papillomavirus type $16 \mathrm{E} 1$ and E2 proteins. J Virol. 1997 Feb;71(2):891-9.

43 Sakai H, Yasugi T, Benson JD, Dowhanick JJ, Howley PM. Targeted mutagenesis of the human papillomavirus type 16 E2 transactivation domain reveals separable transcriptional activation and DNA replication functions. J Virol. 1996 Mar;70(3):1602-11.

44 Hermonat PL, Santin AD, Batchu RB. The adeno-associated virus Rep78 major regulatory/transformation suppressor protein binds cellular Sp1 in vitro and evidence of a biological effect. Cancer Res. 1996 Nov;56(22): 5299-304.

45 Hermonat PL, Santin AD, Batchu RB, Zhan D. The adeno-associated virus Rep78 major regulatory protein binds the cellular TATAbinding protein in vitro and in vivo. Virology. 1998 May;245(1):120-7.

46 Schmidt M, Chiorini JA, Afione S, Kotin R. Adeno-associated virus type 2 Rep78 inhibition of PKA and PRKX: fine mapping and analysis of mechanism. J Virol. 2002 Feb; 76(3):1033-42.

47 Prasad CK, Meyers C, Zhan DJ, You H, Chiriva-Internati M, Mehta JL, et al. The adenoassociated virus major regulatory protein Rep78-c-Jun-DNA motif complex modulates AP-1 activity. Virology. 2003 Sep;314(1):42331.

48 Hermonat PL, Santin AD, Carter CA, Parham GP, Quirk JG. Multiple cellular proteins are recognized by the adeno-associated virus Rep78 major regulatory protein and the amino-half of Rep78 is required for many of these interactions. Biochem Mol Biol Int. 1997 Oct; 43(2):409-20.

49 Sandler AB, Vande Pol SB, Spalholz BA. Repression of bovine papillomavirus type 1 transcription by the E1 replication protein. J Virol. 1993 Sep;67(9):5079-87.

50 Dandapat A, Hu CP, Chen J, Liu Y, Khan JA, Remeo F, Carey RM, et al. Over-expression of angiotensin II type 2 receptor (agtr2) decreases collagen accumulation in atherosclerotic plaque. Biochem Biophys Res Commun. 2008;366(4):871-7. 